\title{
Improve road safety on the basis of cooperation with educational institutions
}

\author{
Michail Devyatov*, Natalia Sapozhkova², Grigoriy Skrylev ${ }^{3}$, Maria Khrunina ${ }^{4}$ \\ Volgograd State Technical University, 400131, Volgograd, Russia
}

\begin{abstract}
Based on the children's road traffic injuries analysis and field pedestrians' behavior observations during the roadway crossing, in order to reduce accidents among pedestrians-children, to create safe approaches to educational institutions is proposed.
\end{abstract}

\section{The project relevance}

In the road safety strategy of the Russian Federation for 2018-2024 [1], one of the main tasks is the road network improvement in terms of improving road safety by low-cost, but effective measures. Foreign experience suggests a possible application of such solutions, which can be used in our country in the pedestrian crossings zone [2,3]. In this case the effect can be achieved in reducing the children's road traffic injuries level. According to estimates of the experts from the European Regional Bureau of the World Health Organization (WHO), about $1,250,000$ people die per year, pedestrians constitute $22 \%$ of the total number of people killed in road traffic accidents. Children are considered particularly vulnerable in such incidents, as the ability to adequately respond to road hazards develops with age. According to the road accidents statistics, only for the current 2019, 42502 accidents occurred on Russian roads, of which 5897 accidents occurred with children under the age of 18, in which 163 children died and 6461 were injured.

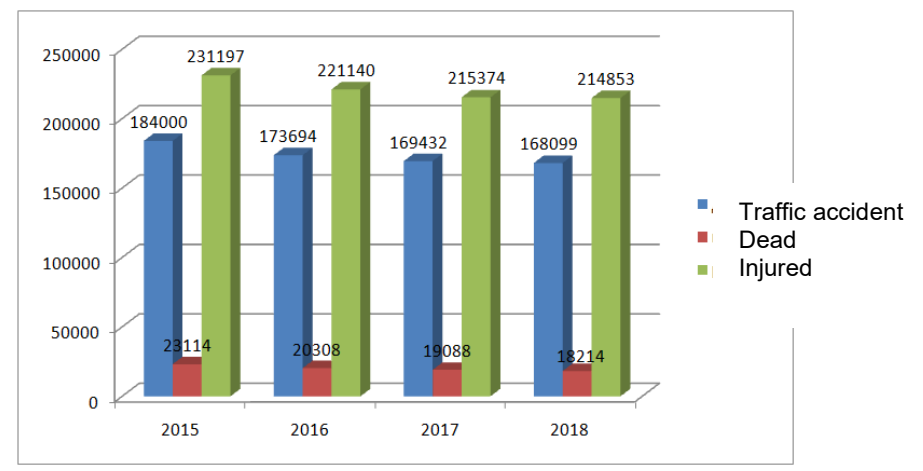

Fig. 1. Road accident statistics for the Russian Federation for 2015-2018

\footnotetext{
*Corresponding author: ipts_vgasu@mail.ru
} 
The accidents in the Russian Federation statistics analysis for 4 years shows a slight decrease in the number of accidents killed and injured. However, the relative rates of accidents are much higher than in Europe. A more detailed analysis of the accident rate was conducted on the road network of Volgograd. It shows that there has been an increase in accidents in 2016-2017 over the past 4 years, and then a decrease in accidents by $13.4 \%$. Since the beginning of 2019, 209 accidents in which 8 dead and 271 injured have been recorded (Fig. 2).

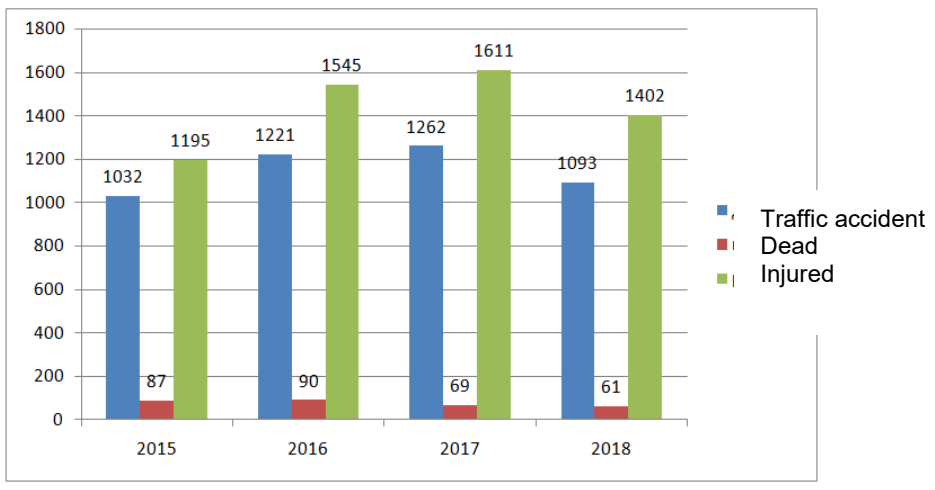

Fig. 2. The accidents statistics in the city of Volgograd for the years 2015-2018.

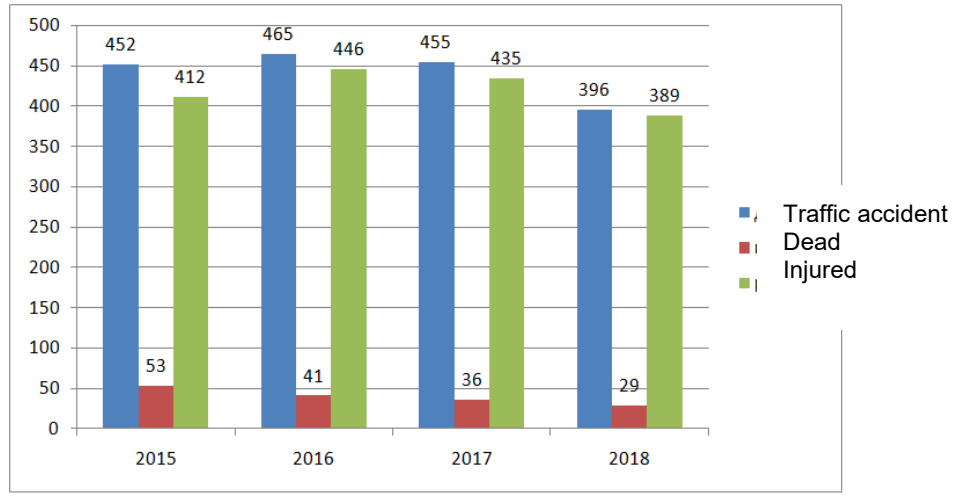

Fig. 3. The traffic accidents statistics involving pedestrians Volgograd for the years 2015-2018

\section{Research}

A more detailed study shows that with the pedestrians' participation from $39 \%$ to $44 \%$ of incidents occur, in which among the wounded $25-35 \% \%$ of pedestrians, and among the dead, this figure reaches $45-60 \% \%$ (Fig. 3). In 2019, 64 road accidents with pedestrians have already been registered, in which 3 people were killed and 65 were injured. 


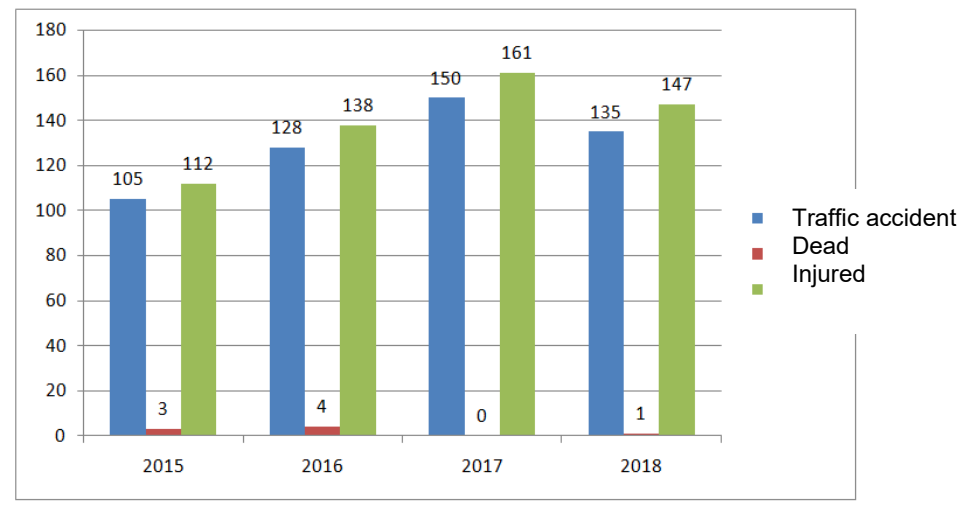

Fig.4. The accidents statistics involving pedestrians under 16 in Volgograd for 2015-2018

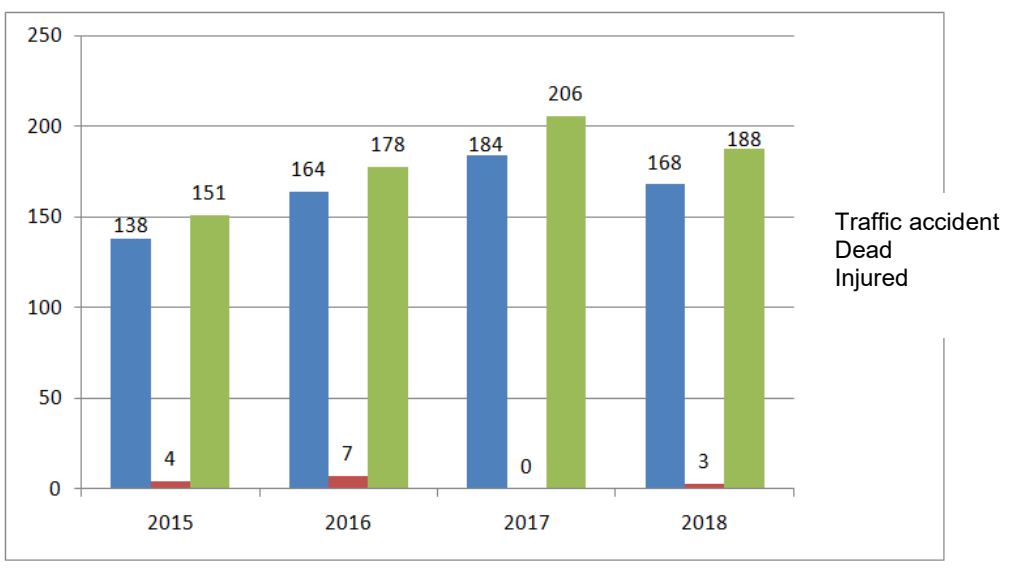

Fig.5. The accident statistics involving pedestrians under 18 in Volgograd for 2015-2018

The study of accidents among children-pedestrians under 16 and 18 years old is of particular concern, because if in 2017 not a single child died in an accident, then in 2018 one child under 16 died and 3 teenagers under the age of 18 died in accidents. At the same time in the first quarter of 2019 with the participation of children-pedestrians under 16 years already 25 accidents and 28 injured, with the participation of teenagers-pedestrians under 18 years 29 accidents, 1 dead and 31 wounded.

The growth of children's road traffic injuries was noticed in Krasnoarmeisky, Sovetsky, Voroshilovsky, Central, Dzerzhinsky districts of the city of Volgograd (Table 1).

At the same time, a study of statistical data on road accidents shows that in the areas with artificial prominencies on the carriageway at the street-road network (SRN) of Volgograd for the period $1995-2018$ the total number of accidents has decreased by $77 \%$ with the total absence of the dead in these places.

The time study of the accident with the participation of children show that most often traffic accidents occurred from 15.00 to 16.00 and from 20.00 to 21.00 (Fig.6). The first-time interval probably corresponds to the time of returning from school after school and may be associated with some children care weakening after intense lessons. This week type by day accidents distribution analysis made it possible to establish that the largest accidents number is at the beginning, Monday-Tuesday (24.1\%) and at the end - Friday-week (22.3\%), which can also indicate some relaxation level and, as a result, inattention after the weekend and at the end of a busy week. This suggests the need for measures to increase care when crossing the road. 
Table 1. The child injuries state for 3 months of 2018 and 2019.

\begin{tabular}{|c|c|c|c|c|c|c|c|c|c|}
\hline \multirow{3}{*}{ District name } & \multicolumn{6}{|c|}{ Child injuries } & \multirow{2}{*}{\multicolumn{3}{|c|}{ Dynamics, \% }} \\
\hline & \multicolumn{3}{|c|}{2018} & \multicolumn{3}{|c|}{2019} & & & \\
\hline & $\begin{array}{c}\text { traffic } \\
\text { accident } \\
\mathrm{s}\end{array}$ & killed & injured & $\begin{array}{c}\text { traffic } \\
\text { accidents }\end{array}$ & killed & injured & $\begin{array}{c}\text { traffic } \\
\text { accidents }\end{array}$ & killed & injured \\
\hline Krasnoarmeysky & 1 & 0 & 1 & 2 & 0 & 3 & 100.0 & 0 & 200 \\
\hline Kyrovsky & 5 & 0 & 5 & 4 & 0 & 4 & -20.0 & 0 & -20 \\
\hline Sovetsky & 2 & 0 & 3 & 3 & 0 & 4 & 50.0 & 0 & 33 \\
\hline Voroshilovsky & 0 & 0 & 0 & 2 & 0 & 2 & 200.0 & 0 & 200 \\
\hline Central & 2 & 0 & 2 & 3 & 0 & 3 & 50.0 & 0 & 50 \\
\hline Dzerzhynsky & 3 & 0 & 3 & 6 & 0 & 7 & 100.0 & 0 & 133 \\
\hline Krasnooktyabrsky & 6 & 0 & 8 & 4 & 0 & 4 & -33.3 & 0 & -50 \\
\hline Traktorozavodsky & 0 & 0 & 0 & 0 & 0 & 0 & 0.0 & 0 & 0 \\
\hline Total & 19 & 0 & 22 & 24 & 0 & 27 & 26.3 & 0 & 22.7 \\
\hline
\end{tabular}

The traffic police statistics study also shows that pedestrians violate the rules 6 times more often when crossing a carriageway than drivers, who do not comply with the requirement to give way to pedestrians and cyclists. So, in Moscow for 2 months 281,120 the traffic laws violations by pedestrians and 47,341 violations by drivers have been revealed [4].

To identify the large number of accidents with pedestrians causes, the authors conducted a study aimed at identifying the people characteristic behavior types when crossing the traffic way. The observations were carried out on the SRN of Volgograd (on the streets of Yeletskaya and Rostovskaya in the middle of the working week from 16:00 to 17:00). As a result of the study, it was found that when crossing the carriageway, only $25.5 \%$ of pedestrians crossed the street in accordance with the traffic laws (TL). The remaining pedestrians showed considerable inattention, and often complete indifference to the ongoing traffic on the road. As a result of the study, the characteristic behavior types of people during the carriageway transition were identified, presented in Table 2. Of particular concern is that among the second group of people, $44.3 \%$ are underage pedestrians.

Table 2. The characteristic behavior of pedestrians during the roadway crossing

\begin{tabular}{|c|c|c|}
\hline \multirow{2}{*}{$\begin{array}{l}\text { Characteristic behavior of people when } \\
\text { crossing the roadway }\end{array}$} & \multicolumn{2}{|c|}{$\begin{array}{c}\text { The number of characteristic behavior } \\
\text { signs }\end{array}$} \\
\hline & people & percent \\
\hline Cross the street in accordance with TL & 90 & 25.5 \\
\hline Not convinced of the crossing safety & 78 & 22.0 \\
\hline Ran across the roadway & 33 & 9.3 \\
\hline $\begin{array}{l}\text { Moved by bike, rollerblading, skateboard, } \\
\text { etc. }\end{array}$ & 16 & 4.5 \\
\hline Got over diagonal & 36 & 10.2 \\
\hline Used the phone & 16 & 4.5 \\
\hline Were with headphones (hood) & 23 & 6.4 \\
\hline \multirow[t]{2}{*}{ Crossed in the wrong place } & 62 & 17.5 \\
\hline & 354 & 100 \\
\hline
\end{tabular}


To change the nature of people's behavior during the carriageway crossing, innovative constructive and organizational methods of improving road safety are proposed.

As a constructive method, a compulsory impact on the trajectory of pedestrians, cyclists, etc. is proposed by orienting the eyes to the passing vehicles in the approaching transport direction (Fig. 6,7). Cyclists, skaters and skateboarders in such conditions will also be forced to stop using their vehicle and be more attentive.

On the territory of Volgograd, there are 357 educational institutions, including 134 schools, 204 kindergartens and 19 supplementary education institutions. Long-term experience shows the measures effectiveness for the Human Rights watch arrangement on the approaches to these institutions and speaks about the expediency of its continuation and improvement with the proposed modern solutions implementation. As guiding devices, the turnstile guards, ornamental islands with green plantings limited by a curbstone and other constructive solutions can be used.

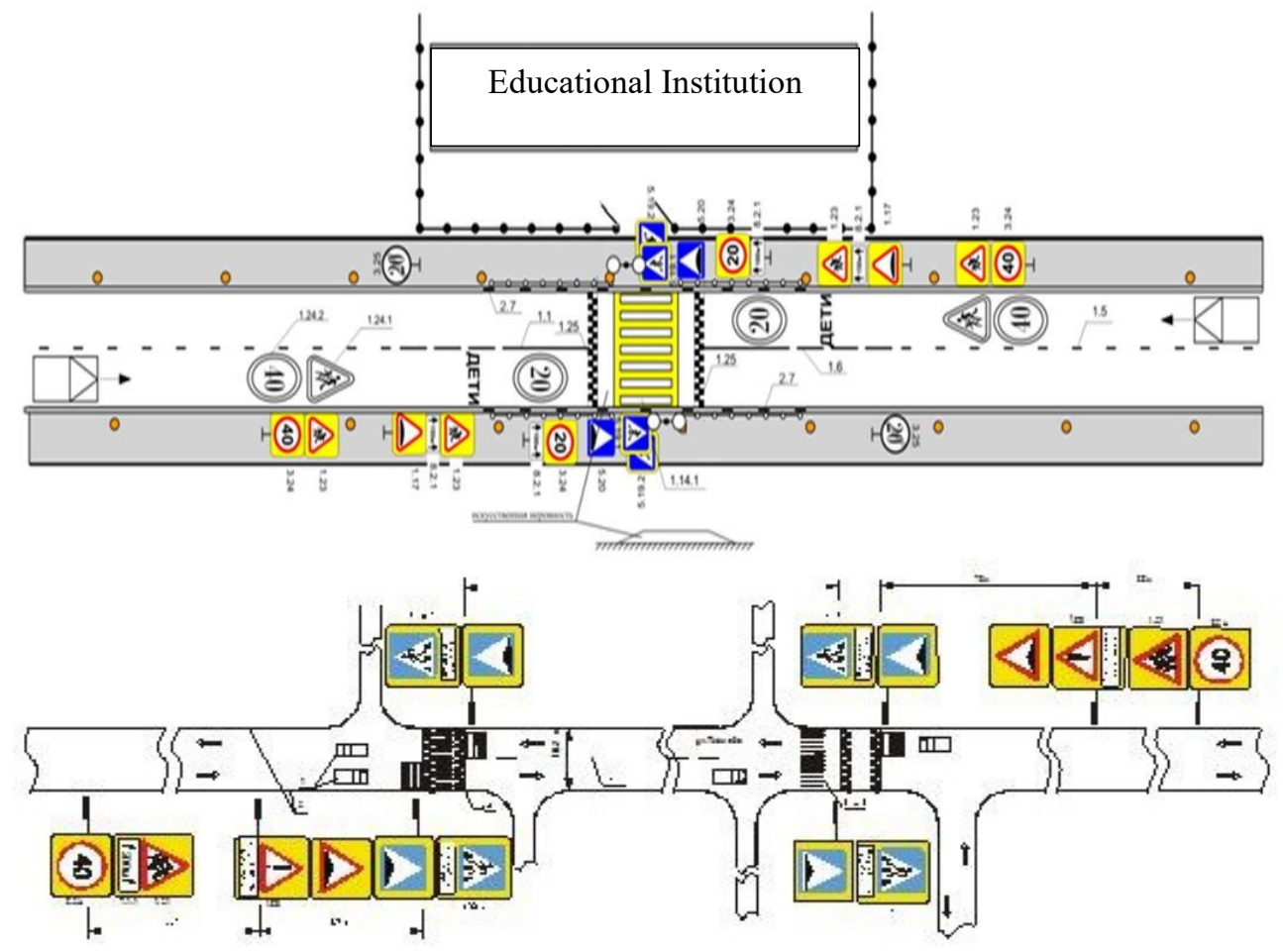

Fig. 6. The transportation planning technical means placement layouts on the approaches to educational institutions - TYPE 1

To ensure the pedestrians' forced orientation, to provide a visual perception of moving vehicles, additional means of fencing and transition sites landscaping (Fig. 9) have been developed and presented in the diagrams. 

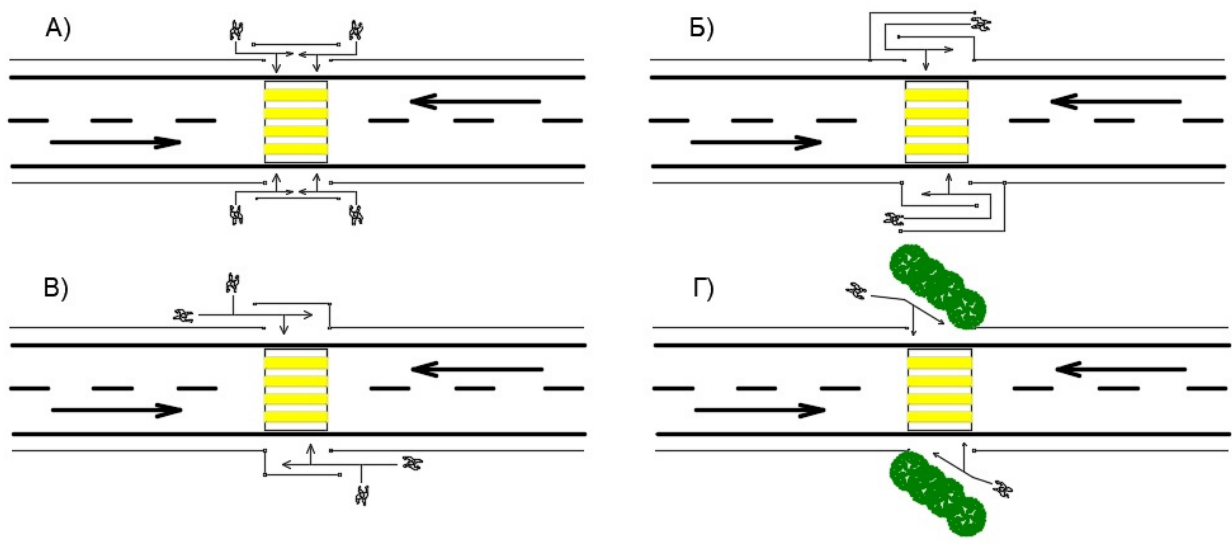

Fig. 7. Schemes proposed to protect the pedestrians from transport using railings (a), (b), (c), and also the "green zone" (d) on the approaches to educational institutions

The proposed schemes orient the pedestrian so that they would look in the approaching transport direction approaching the roadway.

Here, also, when determining the fencing devices dimensions, the cyclists and roller skaters' (who often do not slow down before crossing the roadway) movement peculiarities are taken into account. The proposed schemes force scooters to slow down, and cyclists to "dismount". The fences themselves in the accident event at a site with a pedestrian crossing can protect pedestrians from the transport effects.

As an organizational measure, it is proposed to amend the traffic laws. Their essence consists in changing the exclusive priority right of a pedestrian when going through a pedestrian crossing to a differentiated approach depending on the pedestrian crossing value with the mutual care equating the requirements introduction to drivers and pedestrians. Such a requirement may, for example, relate to pedestrian crossings not equipped with traffic lights. The pedestrians' priority lack will force to be more attentive when passing a carriageway, both pedestrians and drivers, which will reduce the accidents number involving pedestrians. Such changes require, of course, additional research.

\section{Summary}

World statistics show that $22 \%$ of the total number of people killed in road accidents are pedestrians. The accident statistics analysis for the city of Volgograd shows that with the pedestrians' participation from 39 to $44 \% \%$ of all accidents occur, in which among the injured $25-35 \% \%$ of pedestrians, and among the dead, this figure reaches $45-60 \% \%$.

The statistical data study on accidents shows that in the forced impact places on the vehicles speed, by the roadway artificial prominences device on the traffic accidents of Volgograd, for the period 1995-2018. The total number of accidents has decreased by $77 \%$ with the total absence of the dead in these places.

As a result of a study conducted by the authors, it was found that when passing a carriageway, only $25.5 \%$ of pedestrians cross the street in accordance with traffic laws. The remaining pedestrians show considerable inattention, and often complete indifference, to the road traffic, the reasons for which were established during the research. At the same time, in the second group of people $-44.3 \%$ are underage pedestrians.

To change the nature of people's behavior during the passage of a carriageway, innovative constructive and organizational methods of improving road safety are proposed. As a 
constructive method, a compulsory impact on the trajectory of pedestrians, cyclists, etc. is proposed by the preliminary orientation means of a glance crossing the road in the approaching transport direction.

As an organizational measure, it is proposed to introduce changes to the traffic rules aimed at the exclusive priority right of pedestrians when crossing the crosswalk to a differentiated approach depending on the crosswalk value. The pedestrians' unequivocal priority lack will force to be more attentive when crossing the roadway, both pedestrians and drivers, which will reduce the accidents number involving pedestrians.

\section{References}

1. Order of the Government of the Russian Federation of 01/08/2018 N 1-p < On approval of the Road Safety Strategy in the Russian Federation for 2018-2024> http://www.consultant.ru/document/cons doc_LAW 288413/

2. Guidelines for the Selection of Pedestrian Facilities - NZTA (New Zealand Transport Agency, On line at: https://www.nzta.govt.nz/assets/resources/facilities-for-blind-andvision-impaired-pedestrians/docs/guidelines-selection-of-pedestrian-facilities.pdf

3. Pedestrian planning and design guide (NZTA) Page 51: On line at: https://www.nzta.govt.nz/assets/resources/pedestrian-planning-guide/docs/pedestrianplanning-guide.pdf https://www.nzta.govt.nz/resources/pedestrian-planning-guide/

4. On line at: http://stat.gibdd.ru/ 